\title{
British maternal mortality in the 19th and early 20th centuries
}

\author{
Geoffrey Chamberlain
}

J R Soc Med 2006;99:559-563

SECTION OF OBSTETRICS \& GYNAECOLOGY, 22 APRIL 2005

'Death borders upon our birth

And our cradle stands in the grave'

Joseph Hall, Bishop of Exeter (1564-1656)

In the 19th and first half of the 20th century, everybody knew about death in childbirth, particularly those women who were about to go through the process. Although death rates from many other conditions were high, they at least were among people who had been ill beforehand. Death in relation to childbirth was mostly in fit young women who had been quite well before becoming pregnant. They died, often leaving the baby, and other children in the family from previous births, with a widowed husband.

It is only recently that the Church of England prayer book removed the service for the 'churching of women who had recently given birth' which starts by giving thanks to God for:

'The safe deliverance and preservation from the great dangers of childbirth.'

From 1800 to 1950 , maternal mortality was the yardstick for assessing maternity services and it was carefully examined by obstetricians. There were certain problems in defining maternal death (such as the inclusion of those associated with spontaneous abortions) and how long after delivery was the postpartum period. Until 1900 this was 1 month, and after that 6 weeks, with maternal deaths up to 1 year still being noted in Britain. It was also difficult to get the exact numbers of women dying in childbirth, for there was no national counting of deaths. Until the Registration of Deaths Act of 1837, one had to rely upon bills of mortality or parish registers. From such coarse estimates as this were derived the round figures shown in Table 1.

From 1837, the Registrar General's office started to record maternal deaths; this was backed up by invitations from the Presidents of the Royal Colleges and the Master of the Society of Apothecaries to supply voluntarily copies of certificates of death, if possible with cause. It was not until about 1870, when the registration of cause of death was made mandatory, that rates became reasonably accurate.

History of Medicine Unit, School of Medicine, University of Wales Swansea, Wales, UK
Table 1 Estimates of maternal mortality rates (MMR) from records of 13 English parishes in $\mathbf{5 0}$ year periods ${ }^{1}$

\begin{tabular}{lc}
\hline & $\begin{array}{l}\text { MMR per } \mathbf{1 0 0 0} \\
\text { Ilive births }\end{array}$ \\
\hline 1700 to 1750 & 10.5 \\
1750 to 1800 & 7.5 \\
1800 to 1850 & 5.0 \\
\hline
\end{tabular}

Figure 1 records maternal death rates (or, to be more mathematically correct, ratios) from 1850 until 1970. There was a period of irregular but general steady maternal death rates until about 1900 . These then dipped slightly till the First World War and continued so till the late 1930s. Then a sudden precipitous reduction in maternal deaths occurred which could not be due to any natural factors involved in death. It was, in fact, due to the overcoming of maternal infection by chemotherapy and antibiotics.

The Four Horsemen of Death in maternal mortality were puerperal pyrexia, haemorrhage, convulsions and illegal abortion. They still are - in various proportionsmajor killers in most of the world, although their effects are greatly reduced in the UK now.

\section{PUERPERAL PYREXIA}

Deaths from puerperal pyrexiai are rarely seen these days, but it was a major killer in previous centuries. It usually followed an ascending infection of the decidua and particularly to the placental bed. It started 3-10 days after birth and ended in one of three outcomes:

- a pelvic abscess, a localised infection of the pelvis walled off by natural resistance;

- a septic thrombophlebitis leading to septicaemia when bacteria could spread to the pelvic veins. This was usually fatal;

- peritonitis, which was usually a most painful death, when bacteria had travelled up the fallopian tube.

Figure 2 shows how the maternal mortality rate from puerperal pyrexia mirrors the same course as that of the 


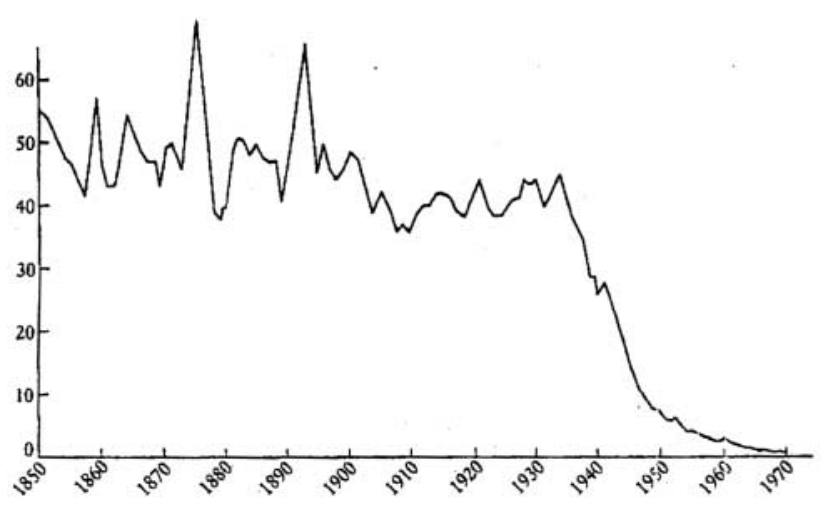

Figure 1 Annual death rate per 1000 total births from maternal mortality in England and Wales (1850-1970) (Registrar General Reports)

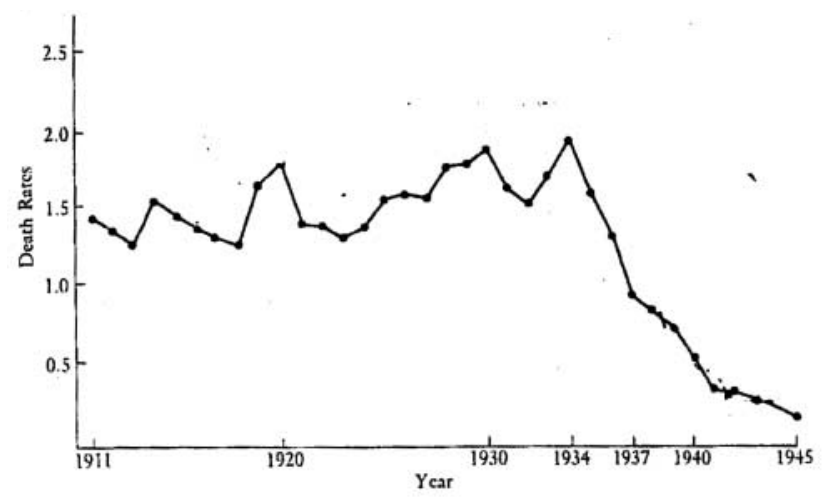

Figure 2 Annual death rates per 1000 total births from puerperal fever in England and Wales (1911-1945) (Registrar General Reports)

total mortality rate shown in Figure 1. Conquering infection was the principal reason for this reduction in mortality.

Puerperal pyrexia was thought to be due to some vapours in the air which could be carried mysteriously from one woman to another. It was only with extreme reluctance that the medical profession accepted that such transmission could be by the birth attendants. Whilst Semelweiss is the best known name in this area, many years before, in 1790, Alexander Gordon (1752-1799) pointed to the passing of some factor from one woman to another by midwives and doctors. Gordon had been a naval surgeon and, whilst on half pay between sea battles, was in London where he attended both Osborne and Denman in their obstetrical lectures. In 1785 he returned to Aberdeen where he was appointed a physician at the Dispensary, where he looked after a variety of medical infections as well as delivering women. In the 1790s, in an epidemic of puerperal fever, he observed the outcome of 77 cases in his care. Gordon showed how the infection was propagated, adding:

$\therefore$.. it is a disagreeable fact that I, myself, was the means of carrying the infection to a great number of women.'2
He suggested that the woman's bedclothes should be burned and that the doctors and nurses involved should carefully fumigate themselves. However, this was not well received and Gordon was hounded from Aberdeen and had to return to the navy. All this was over 50 years before Semmelweis did his work.

Oliver Wendell-Holmes (1809-1894) in America was not an obstetrician, but a physician and poet. He wrote exceedingly well and in consequence was read widely. He found by a series of epidemiological searches that:

$\therefore$. the disease known as puerperal fever is so far contagious as to be frequently carried from patient to patient, by physicians and nurses.' 3

He too was vilified by the medical profession, who would not believe this.

Ignaz Semmelweis (1818-1865) was at the Vienna Maternity Hospital. He considered that puerperal fever was carried on the hands of medical students who had been doing postmortem dissections in the basement of the hospital. He showed very neatly that by washing the hands with carbolic soap before attending women in labour, such cases could be greatly reduced. He did the work in 1847 and he gave a talk on it briefly to the local medical society but it was not until 1858 that he published his book The Aetiology of Childbed Fever. He too was attacked widely by the establishment of obstetricians in Europe, who could not believe that they or their midwife colleagues were responsible for the enormous number of deaths. Semmelwies in his insistence upon hand washing and general cleanliness was the first to emphasize that asepsis had an important part in the prevention of spread of disease. He too was a prophet without honour in his time. Irvine Loudon, an expert on maternal mortality, attributes this both to the reluctance of doctors to accept a single cause for puerperal fever and to Semmelweis' personality - 'his extreme dogmatisim, egocentrcicity and intolerance of even the wildest criticism.' ${ }^{5}$ All three, Gordon, Wendell Holmes and Semmelwies, showed the profession the answer to puerperal infection but they refused to accept it.

Pasteur, the great bacteriologist, in 1879 showed that the streptococcus could be cultured from most cases of puerperal fever, whilst other organisms such as staphylococci and coliform bacilli were often found. This led to an enthusiastic search for antiseptics, chemicals which would kill bacteria. These often harmed the normal tissues to which they were applied. Joseph Lister (1803-1873) introduced a carbolic spray into the operating room to keep the atmosphere above the wound free of bacteria and slowly antisepsis was joined by asepsis, the keeping of bacteria away from open wounds. The latter involved the washing of hands, and the wearing of rubber gloves at 
operations, and the use of face masks to stop droplets from the naso-pharynx and so prevent streptococci from entering the wound area; but it was not until the 1920s that face masks were used in obstetrics. The British College of Obstetricians (later to be the Royal College of Obstetricians and Gynaecologists) in 1929 recommended that at every delivery, masks and rubber gloves, which reached above the elbows, should be worn.

The first chemotherapy in Britain is owed to Leonard Colebrook (1882-1967). He was the Medical Research Council bacteriologist at the Queen Charlotte's infectious diseases unit and had fought long for the use of rubber gloves and proper face masks (with cellophane between the gauge layers) in the labour wards. In January 1936 he introduced prontosil (a sulphonamide) to Queen Charlotte's Hospital with startlingly good results. ${ }^{6}$ This led to the use of many other antibiotics as they appeared in the following 40 years and puerperal sepsis was removed as a major cause of maternal mortality in Britain.

\section{HAEMORRHAGE}

Bleeding is still a major cause of death in many parts of the world; it is one, however, that responds to treatment. Antepartum haemorrhage may be due to placenta praevia or to separation or abruption of the normally sited placenta. Postpartum haemorrhage can follow trauma at delivery, or more usually, because the uterus does not contract down after delivery.

\section{Placenta praevia}

In placenta praevia, the low implanted placenta starts to peel off as the lower segment of the uterus is pulled up in late pregnancy. This is accompanied by maternal bleeding, which can be profuse.

Edward Rigsby (1747-1821) of Norwich had described this in the late 18th century and suggested the use of membrane rupture. ${ }^{7}$ James Young Simpson later described this bleeding from the placental site as placenta praevia, '...a condition which aroused more anxiety in the attendant and was more dangerous to the mother than any other complication of childbirth'.

In the earlier 19th century, if the cervix was closed, the vagina was packed firmly with cloth. Very cold and then very hot douches were sometimes used to staunch the haemorrhage. If the cervix was dilated, Braxton Hicks (1823-1897), an obstetrician of Guy's Hospital, had described in 1860 a combined bipolar version of the baby and then passing a finger through the low lying placenta, bringing down a leg. ${ }^{8}$ This was tied with a tape to a weight over the end of the bed and thus the half-breech was plugged down into the pelvis to reduce or even stop the bleeding. Once the lower segment had been compressed with the half-breech, it was important not to make a rapid delivery of the baby, but to allow the haemorrhage to settle. Labour would follow soon anyway. It was considered at this procedure that there was no need to remove the operator's coat, but that just rolling up the sleeve would suffice. No attempt to clean the hand or arm was made but it was a very successful way of preventing bleeding and it led to a noted reduction of maternal mortality.

Later Lawson Tait (1845-1899) of Birmingham advanced the idea of performing caesarean section for placenta praevia that bled. This was widely taken up. Unfortunately, since many of these women suffered their bleeding early in the third trimester of pregnancy, this often meant the child was born very premature and, in those days, died. It was Charles Macafee (1898-1978) in Belfast who in 1945 advocated admitting the women who had bled to hospital and keeping them there till about 38 weeks of pregnancy when caesarean section was performed. ${ }^{9}$ Excessive bleeding was treated with liberal blood transfusion until 38 weeks. The baby stood a better chance after a delivery at this later stage.

\section{Abruption of the placenta}

Edward Rigby had differentiated the unavoidable antepartum haemorrhage of placenta praevia from the accidental bleeding due to separation of a normally sited placenta. ${ }^{7} \mathrm{He}$ called this 'accidental haemorrhage' and the name stuckas, unfortunately, it was misleading. The American term of abruption of the placenta came to Britain much later. The normally positioned placenta was separated from its bed accompanied by much pain and shock. There was little external bleeding which Rigby described as 'cadaver blood' for it did not clot due to the haematological upset accompanying this condition. The treatment was to rupture the membranes and await a speedy delivery thereafter. This remained the mainstay of treatment until caesarean section became a practical measure in the 20th century. It was only comparatively recently that it was realized that the massive shock was best managed by large replacements of blood, with up to six units being required.

\section{Postpartum haemorrhage}

Whilst some of the excessive bleeding after delivery might be due to damage to the cervix or uterus, most follows the poor contraction of that organ. Sometimes this is associated with the non-delivery of the placenta, in whole or part. Management in the 19th century depended upon knowledge of the physiology of the third stage of labour, which was often misapplied. Sometimes placental delivery was hastened by uncontrolled traction on the cord or by violent pressure on the uterus (Credé manoeuvre). 
Treatment of excessive postpartum bleeding was attempted with vaginal packing, or with cold and later, more effectively, with hot vaginal douches, but the first effective treatment was with ergot, which caused uterine muscles to contract. This has been known of since the 16th century, but it was Oliver Prescott of Massachusetts who, in 1813, described its use for uterine haemorrhage. ${ }^{10}$ Extracts of ergot were given by mouth as 'labour tea'; later ergot was used as an injection after the fetal head was born. Barry Hart of Edinburgh ${ }^{11}$ advocated its use preventively, not waiting for the haemorrhage before injection.

The sorting out of the three alkaloids in crude ergot and the isolation of ergometrine is owed to Chassar Moir (1900-1977), who was working in F J Browne's unit at University College Hospital. ${ }^{12}$ He did extensive research recording intra-uterine pressures after delivery, inserting a balloon into the uterus and recording the pressures via a rubber tube led out of the window of the labour ward, along a ledge and into the next room as the recording instruments were so bulky. Unfortunately, the pigeons of University Street attacked this bright red tube, releasing the mercury and so invalidating the pressure readings. A hole had to be drilled in the wall between the two rooms to continue the experiments. The ultimate value of prophylactic ergometrine in all deliveries was shown by the intramuscular route ${ }^{13}$ and by the intravenous route by John Martin and Jack Dumalin. ${ }^{14}$ The latter compared the postpartum blood loss in a thousand primiparous women with normal deliveries who had intravenous ergometrine at the crowning of the fetal head, with women who had not. Oxytocin came much later in the 1950s, first synthesized in Cornell and its use for reduction of postpartum haemorrhage is increasing. ${ }^{15}$

The battle for reduction of blood loss as a cause of maternal death has been mostly won in the Western world. Unfortunately, these drugs and the skills associated with their use are still not available to everybody in the Developing world.

\section{TOXAEMIA/CONVULSIONS}

It was hard to designate a cause of maternal death to a disease until it had been discovered. Probably it was John Lever (1811-1859), a lecturer in obstetrics at Guy's Hospital, who first recognized the link between protinuria and fits. ${ }^{16}$ Blood pressure measurements did not start until the early days of the next century. Lever wondered if the disease was a manifestation of Bright's disease of the kidney and so this type of maternal death was often classified under renal causes. Its aetiology has been debated widely but its treatment was by sedation with drugs currently available, leading to the technique devised by Stroganoff (1857-1938) in 1898 of controlling fitting by the use of sub-cutaneous morphia and chloroform. ${ }^{17}$ Magnesium sulphate was first used in America in the $1920 \mathrm{~s}^{18}$ and soon spread there to both treat and prevent fitting, but was not picked up in Britain until some 60 years after its widespread use in the USA.

The real management of eclampsia and pre-eclampsia followed its diagnosis and early treatment with hospitalization and bed rest in the 1920s. This was led by Dame Janet Campbell (1877-1954), a medical officer at the Department of Health, who started a national system of antenatal clinics with a uniform pattern of visits. ${ }^{19}$ This led to the boring and repetitive taking of blood pressures and checking urines of millions of women through the world, in order to detect the thousands who were going to develop eclampsia and the hundreds who could have died from convulsions.

\section{ABORTION}

In the 19th century, the medical profession was loathe to discuss illegal abortion and tried to pretend it was all done by midwives and 'guid' women (as in the recently produced film, Vera Drake). One of the best accounts by a doctor was in Somerset Maugham's book Liza of Lambeth, where the heroine dies of septic abortion. Undoubtedly, illegal abortion was common in the 19th and early 20th centuries rising to a peak in the 1930s. It was often disguised on the death certificates as puerperal sepsis or some other cause in order to save the reputation of the family. It is interesting that in this period, it was not mostly unmarried girls in trouble who resorted to abortion, but the 30-40-year-old married women for whom contraception had failed. In this regard, the work of Marie Stopes (1880-1958) in furthering contraception in Britain in the 1920s must be remembered.

The man who dragged the subject of illegal abortion into the public limelight was Alec Bourne (1886-1974), a gynaecologist at St Mary's Hospital who, in 1938, was consulted by a mother and her 13-year-old daughter after the girl had been raped, and they requested a termination of pregnancy. ${ }^{20}$ This he did, having notified the authorities. It was an offence then under the law and he was arrested and tried at the Old Bailey, narrowly escaping a prison sentence. The judge ruled that if two doctors were of the opinion that a woman's health, physical or mental, would be made worse by continuation of pregnancy, they may recommend and perform an abortion. This then went down as Case Law and was converted to Statute Law in 1967 when the Abortion Act was brought before Parliament and passed on a free vote.

Whatever one's ethical ideas are on abortion, this act undoubtedly converted abortion into a procedure performed by those trained in gynaecology rather than amateur 
abortionists, and in association deaths from this cause have gone down in Britain to minute levels. This is not of course true in other parts of the world where, irrespective of faith, illegal abortions still take place and women still die.

\section{REASONS FOR REDUCED MATERNAL MORTALITY RATE}

As shown in Figure 1, the maternal mortality rates have been reduced greatly in the last two centuries, particularly in the last 70 years. Probably the better education of women has led to smaller families at a younger age, and the wider use of contraception, including the pill, has probably allowed better spacing of families. Further, there is a background of better health and nutrition of women in Britain, particularly since the Second World War.

The spread of antenatal care has lessened greatly severe eclampsia rates. The wider use in the last century of antisepsis, asepsis and the introduction of antibiotics in this century, has cut puerperal infection to very low levels. Wider use of blood transfusion with the availability of blood banks and flying squads has reduced the perils of haemorrhage.

Better obstetric and midwifery practice by professionals has undoubtedly reduced the dramatic effects that used to occur in the 19th and early 20th centuries. This can be associated with the influence of the Royal College of Midwives and the Royal College of Obstetricians and Gynaecologists with their training and certification of their professions. The introduction and continuation of the selfaudit of confidential enquiries into maternal deaths started in 1952 and has contributed to greater understanding of maternal deaths. ${ }^{17}$ This is a major cause of improvement in the UK and is considered in an article by James Drife. ${ }^{22}$

Although these factors pertain in North America, Europe and Australasia, this is not true in the developing world, where maternal mortality still accounts for just under a million deaths a year, often from unnecessary and potentially curable causes. Greater aid from the developed world could improve the health and happiness of many families in Africa, Asia and South America. Western governments should be alive to the possibility of increasing assistance and not restricting it because of their own narrow political objectives as do some donors to International Aid Agencies.

Author's note: Those who wish to take this subject further would do well to consult Irvine Loudon's book Death in Childbirth. ${ }^{23}$ It is the authority to which all who write about the 19th and 20th century material available still turn first.

Competing interests None declared.

\section{REFERENCES}

1 Schofield R. Did mothers really die? In: Bonfield L, Smith R, Wrightson K, eds. Histories of Population and Social Structure. Oxford: University Printing House, 1986

2 Lewis G, Minager A. Alexander Gordon of Aberdeen. J Med Biog 2002; 10:150-4

3 Holmes O. On the contagiousness of puerperal fever. N Engl Quart J Med 1842; 1:503-30

4 Gortvay G, Zoltán I. Semmelweis, His Life and Work. Budapest: Akadáemiai Kiadó, 1968

5 Loudon I. Childbirth. In: Loudon I, ed. The Oxford Illustrated History of Western Medicine. Oxford: Oxford University Press, 1997: 214

6 Colebrook L, Kenny M. The treatment with prontosil of puerperal infections due to haemolyte strephococcus. Lancet 1936;ii:1319-22

7 Rigby E. Uterine Haemorrhages Which Preceed The Delivery of The Fullgrown Foetus. London: Johnson, 1775

8 Hicks J B. On a New Method of Version in Abnormal Labour. Lancet $1860 ; \mathbf{i i}: 28-30$

9 Macafee C. Placenta previa - a study of 174 cases. J Obstet Gynaecol Br Emp 1945;52:313-24

10 Prescott O. A Dissertation on the Natural History of Medical Effects of the Secale Cornmutum or Ergot. Andover: Flagg \& Gould, 1813

11 Hart B. Guide to Midwifery. London: Heinemann, 1912

12 Chassar-Moir J. The action of ergot preparations on the puerperal uterus. BMJ 1932:1119-22

13 Daley D. The use of intramuscular ergometine at the end of the second stage of labour. J Obstet Gynaecol Br Emp 1951;58:388-97

14 Martin J, Dumalin J. The use of intravenous ergometine to prevent postpartum haemorrhage. BMJ 1953;i:643-6

15 Du Vigneaud V, Ressler C, Swan JM, Roberts CW, Katsoyannis PG, Gordon S. The synthesis of an oxtopeplide with the hormonal activity of an oxytocin. J Am Chem Soc 1953;75:4879-80

16 Lever J. Cases of puerperal convulsions with remarks. Guy's Hosp Rep 1843;2:495-517

17 LeverStroganoff V. Lecheniyu Eklampsii. Vrach Delo 1900;21: $1137-40$

18 Lazard E M. The intravenous use of magnesium sulphate in puerperal eclampsia. Am J Obstet Gynaecol 1925;9:178-88

19 Campbell J. Maternal Mortality in London, Report 25, vol. 25. London: Ministry of Health 1924: 9-10

20 Bourne A. A Doctor's Creed. London: Victor Gollancz, 1962

21 Confidential Enquiries into Maternal Death Triennial Reports (1952-2005) in England and Wales, Mid Eastern Scotland and N. Ireland. London: HMSO; NUS, 2005

22 Drife J. The history of the confidential enquiries into maternal deaths. Hosp Med (in press)

23 Loudon I. Death in childbirth. An International Study of Maternal Care and Maternal Mortality 1800-1950. Oxford: Clarendon Press, 1992 